\title{
Understanding the Risk-Return Relation: The Aggregate Wealth Proxy Actually Matters
}

\author{
Scott Cederburg* Michael S. O’Doherty ${ }^{\dagger}$
}

December $4,2017^{\ddagger}$

\begin{abstract}
The ICAPM implies that the market's conditional expected return is proportional to its conditional variance and that the reward-to-risk ratio equals the representative investor's coefficient of relative risk aversion. Prior studies examine this relation using the stock market to proxy for aggregate wealth and find mixed results. We show, however, that stock-based tests suffer from low power and lead to biased estimates of the risk-return tradeoff when stocks are an imperfect market proxy. Tests designed to mitigate this bias by incorporating a more comprehensive measure of aggregate wealth produce large, positive estimates of the risk-aversion coefficient around seven to nine.
\end{abstract}

JEL classifications: G10, G12, G17

Key words: Aggregate wealth portfolio, ICAPM, Risk-return tradeoff

*Eller College of Management, University of Arizona, Tucson, AZ 85721. Email: cederburg@email.arizona.edu.

${ }^{\dagger}$ Trulaske College of Business, University of Missouri, Columbia, MO 65211. Email: odohertym@missouri.edu.

${ }^{\ddagger}$ We thank Oliver Boguth, Todd Clark (the Editor), Phil Davies, Luke Devault, Hui Guo, Ranjini Jha, Chris Lamoureux, Seth Pruitt, Neal Stoughton, Paul Weller, an Associate Editor, two anonymous referees, and seminar participants at the 2015 Northern Finance Association meetings and the University of Arizona for helpful comments and suggestions. We also thank Kenneth French for making data available. All errors are our own. 


\section{Introduction}

The Intertemporal Capital Asset Pricing Model (ICAPM) of Merton (1973) implies a positive relation between the market risk premium and market risk. In particular, Merton (1980) shows that the conditional expected excess market return will be proportional to conditional market variance under reasonable conditions, so

$$
E_{t-1}\left(R_{a w, t}\right)=\gamma \sigma_{a w, t}^{2},
$$

where $R_{a w, t}$ is the excess return on aggregate wealth, $\sigma_{a w, t}^{2}$ is the conditional variance of $R_{a w, t}$, and $\gamma$ is the coefficient of relative risk aversion of the representative investor. Merton (1980) specifically demonstrates that equation (1) is a good description of market returns if consumption is more responsive to wealth shocks compared to shocks to investment opportunities or if wealth is more variable than investment opportunities. An extensive literature investigates this risk-return relation by testing whether stock market volatility forecasts stock returns. Early results on the riskreturn relation for stocks were mixed, as Campbell (1987) finds a negative relation whereas French, Schwert, and Stambaugh (1987) find evidence of an insignificant or positive association between volatility and expected returns. Many additional studies employ different methods for estimating conditional volatility and assessing the risk-return tradeoff. Inferences have continued to vary, however, with researchers producing evidence of significantly positive, significantly negative, or insignificant risk-return relations in the stock market.

The ICAPM has implications for the association between conditional volatility and expected return for the aggregate wealth portfolio, but existing literature investigates this prediction using the stock market portfolio as a proxy for aggregate wealth. The validity of inferences from assetpricing tests using aggregate market proxies often requires only a relatively high correlation between the true market portfolio and its proxy portfolio (e.g., Kandel and Stambaugh (1987) and Shanken (1987)). In the context of the risk-return relation in equation (1), however, much stronger conditions for the market proxy are necessary. In particular, we show that using the stock market portfolio as a proxy for aggregate wealth is likely to bias the risk-return coefficient toward zero even if the returns of stocks and aggregate wealth are perfectly correlated.

To formalize the importance of the aggregate wealth proxy, we consider empirical tests of the following analogue of equation (1) in which stocks serve as the market proxy:

$$
E_{t-1}\left(R_{s, t}\right)=\gamma_{s} \sigma_{s, t}^{2}
$$


Drawing from prior literature, we assess the relation in equation (2) using a two-step approach in which stock returns are forecasted with the fitted conditional variance from a generalized autoregressive conditional heteroskedasticity (GARCH) model using a standard OLS regression. If stocks are a perfect proxy, this test produces an unbiased estimate of the risk-return coefficient $\gamma$. If stocks are an imperfect proxy, on the other hand, equation (2) is not an implication of the ICAPM and the corresponding test is potentially problematic. In particular, we show in Section 3 that under reasonable conditions

$$
\gamma_{s}=\rho \frac{\sigma_{a w}}{\sigma_{s}} \gamma
$$

where $\rho$ is the unconditional correlation of stock market and aggregate wealth portfolio returns.

The relation in equation (3) implies that stock-based tests generally produce biased estimates of the coefficient of relative risk aversion. In particular, risk-return tests with stocks generate downward-biased estimates of $\gamma$ if stock market returns are more volatile than aggregate wealth returns (i.e., $\sigma_{s}>\sigma_{a w}$ ), which is consistent with common intuition. Anecdotal evidence further indicates that this bias is likely substantial in empirical applications. For example, Stambaugh (1982) produces evidence that the NYSE stock index is 2.8 to 4.8 times more volatile than his proxy for aggregate wealth (Index no. 3). This evidence also suggests a much weaker true relation between expected stock returns and conditional stock market variance than would be predicted by the ICAPM if stocks were a perfect proxy.

Motivated by this analysis, the objectives of this paper are to (i) formally characterize the magnitude of the bias that is likely present in prior studies of the risk-return relation and assess the impact of this bias on stock-based tests and (ii) propose and implement a series of alternative methods for estimating the coefficient of relative risk aversion. These tasks require us to construct a more comprehensive estimate of aggregate wealth portfolio returns. Exact measurement of returns to aggregate wealth is notoriously difficult, but we propose a proxy for total wealth based on aggregate financial and nonfinancial holdings of the households and nonprofit sector as reported in the Federal Reserve Flow of Funds report. This proxy allows for considerably more complete coverage than the stock market proxy used in earlier literature, as we also account for holdings of noncorporate businesses, deposits, bonds, mutual funds, pension assets, and real estate. Stocks comprise under $20 \%$ of our aggregate wealth portfolio on average, so other asset classes are important for measuring aggregate wealth returns. Given our definition for aggregate wealth, the unconditional correlation between stocks and aggregate wealth is 0.92 and the unconditional standard deviations 
are $1.94 \%$ and $4.35 \%$ per month for the aggregate wealth and stock market portfolios, respectively. The relation in equation (3) therefore implies that $\gamma_{s}$ understates the magnitude of the coefficient of relative risk aversion by about $60 \%$.

The bias in the risk-return coefficient from stock-based tests has two primary effects on ICAPM inferences. First, the true relation between expected stock returns and conditional stock variance is considerably weaker when stocks are an imperfect proxy, which substantially reduces test power. We demonstrate that empirically identifying a significantly positive risk-return relation becomes difficult compared to the perfect-proxy case, which is consistent with the lack of consensus in previous literature about the risk-return relation for stocks. Second, stock-based tests generally produce poor estimates of the coefficient of relative risk aversion. To quantify the magnitude of the bias in the data, we empirically investigate the risk-return relation for stocks using a two-step approach that relates stock returns to GARCH conditional variance estimates. This method generates marginally statistically significant evidence of a positive risk-return relation with a coefficient estimate of 3.10 (one-tailed $p$-value of 0.06). Equation (3) implies a bias-corrected $\gamma$ estimate of 7.60 in this case, which suggests that the bias in stock-based tests is large and economically meaningful.

We proceed to introduce three alternative approaches to directly obtain unbiased estimates of $\gamma$ assuming that our aggregate wealth proxy is accurate. The first proposed test of the ICAPM follows directly from equation (1). We estimate this model using our aggregate wealth portfolio returns data via the two-step approach. Our second test follows from the ICAPM prediction that stock market expected returns should be proportional to the conditional covariance of stocks with aggregate wealth,

$$
E_{t-1}\left(R_{s, t}\right)=\gamma \sigma_{s, a w, t}
$$

We estimate the conditional covariance in equation (4) using the BEKK bivariate GARCH model of Engle and Kroner (1995) and then regress stock market returns on this covariance estimate. Finally, we investigate ICAPM implications using a series of panel regressions that each incorporate multiple test assets including: (i) eight aggregate wealth component asset classes and our aggregate wealth portfolio, (ii) size decile portfolios, (iii) book-to-market decile portfolios, and (iv) momentum decile portfolios. An analogue of equation (4) holds for each asset, and we use a two-step approach to estimate $\gamma$ for each set of test portfolios.

Each of these methods produces an estimate of the coefficient of relative risk aversion that is close to the bias-corrected coefficient from the stock-based test. Across the alternative approaches, the estimates of $\gamma$ range from 7.16 to 9.29. These estimates are significantly greater than zero 
at conventional levels, such that we are able to produce strong statistical evidence of a positive risk-return tradeoff. In sum, we find evidence of a large and positive reward for risk that is similar in magnitude for tests based on the expected returns of the aggregate wealth portfolio, the stock market, and broad sets of assets.

The paper is organized as follows. Section 2 reviews related literature. Section 3 shows that inferences about risk and return are sensitive to the specification of the aggregate wealth proxy and discusses the associated effects on test properties. Section 4 provides details on the construction of our proxy for the aggregate wealth portfolio. Section 5 re-examines tests of the risk-return relation for stocks and computes bias-corrected estimates of the coefficient of relative risk aversion. Section 6 presents alternative ICAPM tests that produce unbiased risk-return coefficients conditional on our aggregate wealth proxy and explores additional implications of our aggregate wealth portfolio for asset pricing tests. Section 7 concludes.

\section{Literature Review}

Several studies investigate the relation between the expected return and conditional variance of stocks. In early work, French, Schwert, and Stambaugh (1987) find a positive risk-return relation using a GARCH model with mean effects (GARCH-M) and an insignificant relation when estimating conditional volatility using an autoregressive integrated moving average (ARIMA) model, whereas Campbell (1987) shows a negative relation using an instrumental variables approach to estimate volatility. Many studies revisit the risk-return issue while introducing alternative methods for estimating the conditional variance of stocks and/or different time-series approaches to relating risk and return. In particular, researchers find positive relations between expected returns and conditional volatility based on GARCH-M (Chou (1988)), mixed data sampling (MIDAS) (Ghysels, Santa-Clara, and Valkanov (2005)), implied volatility (Bollerslev and Zhou (2006)), high-frequency data (Bali and Peng (2006)), dynamic factor analysis (Ludvigson and Ng (2007)), an extended sample period (Lundblad (2007)), and implied cost of equity as a proxy for expected return (Pástor, Sinha, and Swaminathan (2008)). Negative risk-return relations are estimated using conditional volatility estimates from regime-switching models (Turner, Startz, and Nelson (1989)), exponential GARCH (EGARCH) (Nelson (1991)), modified GARCH-M and EGARCH with mean effects (EGARCH-M) (Glosten, Jagannathan, and Runkle (1993)), a latent vector autoregressive (VAR) process (Brandt and Kang (2004)), realized variance in high-frequency data (Bollerslev, Osterrieder, Sizova, and Tauchen (2013)), and forecasted realized variance (Bekaert and Hoerova (2014)). Other 
studies find insignificant relations when conditional volatility is measured using GARCH-M (Baillie and DeGennaro (1990)), quadratic GARCH with mean effects (QGARCH-M) (Campbell and Hentschel (1992)), conditioning information (Whitelaw (1994)), seminonparametric density estimation (Harrison and Zhang (1999)), prior month squared returns (Goyal and Santa-Clara (2003) and Bali, Cakici, Yan, and Zhang (2005)), prior month realized variance (Bollerslev, Tauchen, and Zhou (2009)), and overlapping data inference (ODIN) (Hedegaard and Hodrick (2016)).

Our finding that the proxy for aggregate wealth is important in risk-return tests is useful for interpreting the evidence in this literature. In particular, we show that the relation between risk and return in stocks is likely to be much weaker than would be anticipated if stocks were a perfect proxy for aggregate wealth. Producing statistical evidence of a positive risk-return relation is more difficult as a result, which may contribute to the disagreement in previous literature. In related work, Lundblad (2007) studies the properties of tests for a positive risk-return relation in stocks assuming that the stock market is a perfect proxy for aggregate wealth. In this framework, Lundblad (2007) emphasizes that the commonly used tests in the literature have low power to identify a significant risk-return relation. In response to the low power issue, he suggests testing the ICAPM using very long time series of returns. In contrast to Lundblad (2007), we allow for the possibility that stocks are an imperfect proxy for aggregate wealth and find that test power is substantially reduced relative to the perfect-proxy case in this scenario.

Our paper also has implications for alternative tests of the time-series predictions of the ICAPM. Following the bulk of the literature, we investigate the model for conditional expected excess market returns in equation (1), such that the risk premium is proportional to conditional market volatility and the price of risk is determined by a constant coefficient of relative risk aversion. Previous studies examine variations of this model. First, Scruggs (1998), Scruggs and Glabadanidis (2003), Guo and Savickas (2006), Guo and Whitelaw (2006), Hedegaard and Hodrick (2014), and Rossi and Timmermann (2015) study the risk-return relation while considering additional intertemporal risk factors, such that the market risk premium is not proportional to conditional variance. Second, Campbell, Giglio, Polk, and Turley (2017) develop an intertemporal CAPM with stochastic volatility and show that the conditional expected market return is proportional to conditional market volatility, but the risk-return relation is not necessarily governed solely by the coefficient of relative risk aversion. Third, Whitelaw (1994), Harvey (2001), Brandt and Kang (2004), Ludvigson and Ng (2007), and Lettau and Ludvigson (2010) allow for potential variation in the risk-return relation, which could be caused by a time-varying coefficient of relative risk aversion. Our general critique that the reward for risk is likely to be mismeasured if the stock market is used as a proxy for 
aggregate wealth applies to these alternative settings. Our goal in this paper is to demonstrate the influence of the aggregate wealth proxy on estimates of the risk-return relation in a parsimonious framework, but examining the effects of the wealth proxy on inferences in other test designs is an important avenue for future research.

\section{$3 \quad$ ICAPM Inferences and the Aggregate Wealth Proxy}

As previously discussed, many studies investigate the risk-return relation implied by the ICAPM while using the stock market portfolio as a proxy for aggregate wealth. Assuming that stocks are a perfect proxy, the ICAPM implies

$$
E_{t-1}\left(R_{s, t}\right)=\gamma \sigma_{s, t}^{2}
$$

where $R_{s, t}$ is the excess return and $\sigma_{s, t}^{2}$ is the conditional variance of the stock market. Researchers have developed several methods for empirically examining this relation using alternative measures for stock variance and different specifications to relate returns to risk. Given estimates of conditional stock market variance, a straightforward approach is to estimate a predictive regression for stock returns with conditional variance as the predictive variable,

$$
R_{s, t}=\mu+\gamma_{s} \hat{\sigma}_{s, t}^{2}+\eta_{s, t}
$$

where the risk-return coefficient $\gamma_{s}$ can be interpreted as the coefficient of relative risk aversion $\gamma$.

Stocks are likely to be an imperfect proxy for aggregate wealth, however, and stock market returns must be exactly equal to aggregate wealth returns each period for equation (5) to be strictly valid. More generally, the ICAPM implies that all assets are priced based on their covariance with aggregate wealth returns, such that expected stock returns are determined by

$$
E_{t-1}\left(R_{s, t}\right)=\gamma \sigma_{s, a w, t}
$$

where $\sigma_{s, a w, t}$ is the conditional covariance between stock market returns and aggregate wealth returns. In this case, we show that the predictive regression in equation (6) produces a biased estimate of $\gamma$ and has low power for establishing a positive risk-return relation for stocks.

For the purposes of deriving analytical solutions, we assume that aggregate wealth and stock market returns jointly follow the scalar BEKK bivariate GARCH model of Engle and Kroner (1995). 
Specifically,

$$
\left[\begin{array}{c}
R_{a w, t} \\
R_{s, t}
\end{array}\right]=\pi_{t}+\varepsilon_{t}, \quad \varepsilon_{t} \sim N\left(0, \Sigma_{t}\right),
$$

where $\pi_{t}$ is a vector of conditional expected returns, and the conditional variance-covariance matrix

$$
\Sigma_{t} \equiv\left[\begin{array}{cc}
\sigma_{a w, t}^{2} & \sigma_{s, a w, t} \\
\sigma_{s, a w, t} & \sigma_{s, t}^{2}
\end{array}\right]
$$

evolves according to

$$
\Sigma_{t}=\Omega+\alpha\left(\varepsilon_{t-1} \varepsilon_{t-1}^{\prime}\right) \alpha+\delta \Sigma_{t-1} \delta
$$

where $\alpha$ and $\delta$ are scalars. The BEKK GARCH framework produces conditional variances for both the aggregate wealth and stock market portfolios as well as the conditional covariance between the portfolios. If the ICAPM holds, expected returns are given by

$$
\pi_{t}=\left[\begin{array}{c}
\gamma \sigma_{a w, t}^{2} \\
\gamma \sigma_{s, a w, t}
\end{array}\right]
$$

In this setting, estimating the predictive regression in equation (6) generally produces a biased estimate of $\gamma$. In particular, we show in the Internet Appendix that

$$
\begin{aligned}
\gamma_{s} & =\frac{\operatorname{Cov}\left(R_{s, t}, \sigma_{s, t}^{2}\right)}{\operatorname{Var}\left(\sigma_{s, t}^{2}\right)} \\
& =\rho \frac{\sigma_{a w}}{\sigma_{s}} \gamma
\end{aligned}
$$

The relation in equation 12 implies that $\gamma_{s}$ can be a biased estimate of $\gamma$ even if stocks and aggregate wealth are perfectly correlated. Further, empirical estimates suggest that the bias is economically large. Estimates of $\rho, \sigma_{a w}$, and $\sigma_{s}$ from Stambaugh (1982) and Lustig, Van Nieuwerburgh, and Verdelhan (2013) produce a range of 0.14 to 0.35 for the quantity $\rho \frac{\sigma_{a w}}{\sigma_{s}}$. Using the aggregate wealth portfolio that we construct below, $\rho \frac{\sigma_{a w}}{\sigma_{s}}$ estimates range from 0.38 to 0.41 depending on whether we estimate the components using sample statistics or within the context of the BEKK GARCH framework.

Equation (12) also has important implications for understanding the empirical evidence from prior literature that tests for a risk-return relation among stocks. For a given $\gamma$, equation (12) implies that the relation between expected stock returns and conditional stock market volatility 
is likely to be much less pronounced when stocks are an imperfect proxy for aggregate wealth. As a consequence, establishing statistical evidence of a positive relation between risk and return among stocks will be more difficult relative to the idealized setting of the perfect-proxy ICAPM implication in equation (5). Moreover, the magnitude of the bias in $\hat{\gamma}_{s}$ implied by the empirical estimates suggests that the reduction in test power may be substantial.

We further investigate the power of these tests in the Internet Appendix using a Monte Carlo approach within a diagonal BEKK GARCH framework. In particular, we simulate samples of stock market and aggregate wealth returns that match the features and length of our empirical sample and investigate the properties of risk-return tests when stocks either are or are not a perfect proxy. We find that the probability of obtaining statistical evidence of a positive risk-return relation for stocks is substantially reduced when stocks are an imperfect proxy. For example, whereas a positive risk-return relation can be established in $80 \%$ of simulated samples in which stocks are a perfect proxy with $\gamma=5$, only $25 \%$ of draws in this setting produce statistically significant evidence when stocks are an imperfect proxy for aggregate wealth. Given the low power in stock-based tests, it is perhaps unsurprising that previous literature does not reach a consensus on the relation between the expected return and conditional variance of stocks.

\section{Data}

The results in Section 3 suggest that researchers should exercise caution in interpreting results from stock-based tests of the ICAPM, particularly when the economic magnitude of the risk-return coefficient is of interest. Motivated by these concerns, we propose a more comprehensive measure of returns for the aggregate wealth portfolio. This section provides an overview of the asset classes included in our aggregate wealth proxy and our approach to estimating asset-class weights and returns. We use the resulting aggregate wealth return series in Section 5 to quantify the potential magnitude of the biases in risk-return coefficients from stock-based tests. This aggregate wealth portfolio also underlies the empirical tests developed in Section 6 intended to produce unbiased estimates of the risk-return tradeoff in the ICAPM. In the Internet Appendix, we provide additional details on the construction of our aggregate wealth proxy, discuss asset classes excluded from our measure of aggregate wealth (e.g., human capital and consumer durable goods), and demonstrate that our main empirical findings are robust to alternative specifications of the aggregate wealth portfolio.

We consider several asset classes for inclusion in the aggregate wealth portfolio, and our starting 
point for assigning portfolio weights is the Balance Sheet of Households and Nonprofit Organizations from the Federal Reserve Flow of Funds Table B.100. This table summarizes levels of nonfinancial assets (e.g., real estate and consumer durable goods), financial assets (e.g., deposits, credit market instruments, and corporate equities), and liabilities for the households and nonprofit sector. The aggregate holdings in the Flow of Funds tables are available on a quarterly basis starting at the end of December 1951.

Starting from Flow of Funds Table B.100, we select individual asset classes for which we are able to obtain a sufficiently long history of reliable returns data. We require monthly returns given that lower frequency (e.g., annual) data would not allow for reasonable estimates of volatility in our ICAPM tests. In the end, we consider nine component asset classes in constructing the aggregate wealth proxy: corporate equity, noncorporate equity, deposits, Treasury debt, agency debt, municipal debt, corporate debt, defined benefit (DB) pensions, and real estate. On average, the asset classes included in our aggregate wealth proxy account for $85.4 \%$ of the total financial and nonfinancial assets (net of home mortgages) reported in Flow of Funds Table B.100. As discussed below, our real estate return series starts in January 1953, which is close to the start of the Flow of Funds data. As such, we set the sample period in the paper as January 1953 to December 2013.

In constructing the aggregate wealth portfolio, we weight each asset class in proportion to aggregate asset holdings of households and nonprofit organizations from the Federal Reserve Flow of Funds tables. We update portfolio weights on a quarterly basis in accord with the reporting frequency of the Flow of Funds data. Using the holdings of households helps to avoid the double counting of assets, which is a primary concern when calculating aggregate values of asset classes. For example, much of the corporate equity issued by public firms is held by other public firms. The value of these securities also contributes to the value of the owner, so the total value of corporate equities overstates the contribution of public stock to aggregate wealth. Measuring only those assets that are held by individuals avoids this issue to the extent possible.

Another concern in constructing weights is that households indirectly hold corporate equities and other assets through intermediaries including mutual funds and defined contribution pension plans. The Flow of Funds release includes additional supplementary tables summarizing indirect equity holdings (Table B.100.e) and breakdowns of assets held in mutual funds (Table L.121) and private defined contribution plans (Table L.117.c). This detail allows us to allocate the indirect components of household wealth across the individual asset classes.

Panel A of Table 1 reports summary statistics for the weights of each asset class. Corporate equity makes up just under $20 \%$ of aggregate wealth on average. The corporate equity asset class 
includes publicly traded common stock as well as privately held corporations and preferred stock of public firms. Thus, this category somewhat overstates the contribution to aggregate wealth of the stock market portfolio that serves as the market proxy in prior literature. Further, the weights are highly time varying as displayed in Figure 1. During the sample period, the weight in corporate equities ranges from $8.6 \%$ to $36.6 \%$. Real estate makes up approximately $23 \%$ of wealth on average, whereas deposits, noncorporate equity, and defined benefit pensions each have average weights between $15 \%$ and $20 \%$. Direct household ownership of longer-term debt instruments is relatively small with Treasury, agency, municipal, and corporate debt combining to an average weight of just over $6 \%$.

We construct a monthly return series for each of the nine asset classes. We briefly describe the sources of the returns data here and provide full details in the Internet Appendix. For our corporate equity series, we use returns on the CRSP value-weighted index. Returns on noncorporate equity are not directly measurable, but returns on various assets that may be similar to private companies tend to be closely related to returns of small, publicly traded stocks. For example, private equity and venture capital funds (e.g., Cochrane (2005)) as well as recent initial public offering stocks (e.g., Brav and Gompers (1997)) tend to be highly correlated with a small stock portfolio. As such, we use returns for the smallest decile of size-sorted portfolios available on Kenneth French's website (http://mba.tuck.dartmouth.edu/pages/faculty/ken.french/) to proxy for noncorporate equity returns. The time series of returns for deposits, Treasury debt, and corporate debt are constructed from the Ibbotson SBBI Classic Yearbook. We use the Bank of America Merrill Lynch U.S. Agency Index and the Bank of America Merrill Lynch U.S. Municipal Securities Index to measure returns on agency debt and municipal debt, respectively. Both of these indexes are available through Bloomberg.

Reliable estimates for the returns on pension assets and real estate are somewhat more challenging to construct. Our definition of pension assets covers defined benefit pension plans that are offered by either the private sector or the governmental sector at local, state, and federal levels. We therefore approximate defined benefit pension returns using a portfolio of corporate and government bonds, with weights determined by the relative values of private pension plans for the corporate bond series and local, state, and federal government pension plans for the government bond series. This proxy reflects the sensitivity of pension assets to interest rates (e.g., Black (1989)) and potential private sector pension plan insolvency in extreme circumstances associated with corporate distress events (e.g., Poterba, Rauh, Venti, and Wise (2007) and Novy-Marx and Rauh (2011)). Finally, real estate returns are constructed from Consumer Price Index (CPI) data 
on housing costs.

The real estate return series is available starting in January 1953, which we set as the beginning of our sample period. The indexes used to proxy for agency debt and municipal debt start in January 1978 and January 1989, respectively. We include these assets in the aggregate wealth portfolio as the returns become available. The returns for all remaining asset classes span the full sample period.

Table 1, Panel B reports summary statistics for the monthly excess return series for the aggregate wealth portfolio and each of the considered asset classes. We convert all returns to excess returns by subtracting the 30-day Government Bond index return from Ibbotson. The aggregate wealth portfolio has lower average returns and volatility relative to the corporate equity portfolio. In particular, the aggregate wealth portfolio has an average excess return of $0.29 \%$ per month compared to $0.58 \%$ for the stock market. The standard deviation of aggregate wealth returns is $1.94 \%$, less than half of the $4.35 \%$ standard deviation of stocks. Further, the aggregate wealth portfolio has much less extreme minimum $(-7.55 \%$ versus $-23.24 \%)$ and maximum $(8.05 \%$ versus $16.10 \%)$ monthly excess returns. The relatively low volatility of aggregate wealth is perhaps unsurprising after examining the alternative asset classes that are included in the aggregate wealth portfolio. With the exception of noncorporate equity, the remaining asset classes have average excess returns and standard deviations that are low compared to corporate equity with average excess returns between $-0.04 \%$ and $0.24 \%$ per month and standard deviations ranging from $0.00 \%$ to $2.50 \%$ per month.

Greater diversification for the aggregate wealth portfolio results in a monthly Sharpe ratio of 0.15 compared to 0.13 for the stock market portfolio. In the Internet Appendix, we demonstrate that several of the alternative asset classes can improve portfolio performance measured by the Sharpe ratio when added to a position in stocks. In particular, positive positions in four of the remaining seven asset classes (Treasury debt, agency debt, municipal debt, and defined benefit pensions) produce statistically significant increases in the portfolio Sharpe ratio when they are combined with the corporate equity portfolio. In contrast, an investor with a position in the aggregate wealth portfolio only realizes a statistically significant improvement in the Sharpe ratio by increasing the weight in one asset class (agency debt). Additionally, a stock-based investor would significantly expand the mean-variance frontier by adding a position in the aggregate wealth portfolio, whereas an aggregate-wealth-based investor would not benefit from altering the weight on stocks. Thus, in the context of mean-variance portfolio choice and CAPM settings, our aggregate wealth portfolio appears to be superior to the stock market portfolio. 
Panel B of Table 1 also shows that several return series display substantial autocorrelation. Positive autocorrelation in returns may appear for a particular asset class if variation in persistent expected returns over the sample period is large relative to the period-by-period volatility. Alternatively, nonsynchronous return measurement could lead to the appearance of autocorrelation. Nonsynchronicities are a potential concern with measured returns for some asset classes such as noncorporate equity (e.g., Lo and MacKinlay (1990)) and real estate (e.g., Stambaugh (1982)), so we also consider versions of our tests that account for this feature of the data.

Panel C displays correlations across return series. Interestingly, the correlation between aggregate wealth and stock market returns is large and positive at 0.92. As discussed in Section 3 , estimates from the risk-return tests we consider in our main analyses are affected by other return characteristics, such that a high correlation between returns to stocks and aggregate wealth is not sufficient to draw proper inferences when stocks are used as the aggregate wealth proxy.

Before proceeding, we acknowledge that our proxy for aggregate wealth is likely to be imperfect. The return on the ICAPM's market portfolio is inherently unobservable (e.g., Roll (1977)), and readers may have a wide range of reasonable views that differ from ours on the appropriate specification for aggregate wealth. Our proposed measure incorporates a broad set of asset classes in a systematic fashion, and we also demonstrate that our findings are robust to several alternative approaches to estimating asset-class weights and returns in the Internet Appendix. Nonetheless, measurement error is potentially introduced in constructing portfolio returns as a result of missing asset classes or due to mis-measured weights or returns. We therefore provide a formal analysis in the Internet Appendix of whether the bias in the estimated coefficient of relative risk aversion implied by equation 12 is likely to be larger in magnitude using stocks versus our proxy. We find that the measurement error in our proxy must be both large and strongly negatively correlated with the true aggregate wealth portfolio returns in order for our proxy to underperform relative to stocks in testing the risk-return relation. We also show that our proxy will produce a smaller magnitude of bias in $\gamma$ estimates if the standard deviation of aggregate wealth portfolio returns is less than $2.7 \%$ per month, which is a condition that is met by our proxy as well as estimates from prior studies (e.g., Stambaugh (1982) and Lustig, Van Nieuwerburgh, and Verdelhan (2013)). Overall, our paper highlights first-order concerns with stock-based tests of the ICAPM that have dominated the literature to this point and offers estimates of the coefficient of relative risk aversion that mitigate these problems. 


\section{Revisiting the Risk-Return Relation for Stocks}

In this section, we examine the relation between expected return and conditional variance for the stock market portfolio. As shown in Section 3, tests relating expected stock returns to conditional stock market variance are likely to produce biased estimates of the coefficient of relative risk aversion. Given our analytical results in Section 3 and the aggregate wealth portfolio developed in Section 4, however, we can estimate the empirical magnitude of this bias and produce biascorrected $\gamma$ estimates following equation 12 .

Our empirical tests evaluate the risk-return relation using a two-step approach. We first estimate conditional volatility using a GARCH model in which demeaned excess returns for the stock market portfolio are normally distributed,

$$
R_{s, t}-\bar{R}_{s} \sim N\left(0, \sigma_{s, t}^{2}\right)
$$

and conditional variance $\sigma_{s, t}^{2}$ is given by

$$
\sigma_{s, t}^{2}=\omega+\alpha \varepsilon_{s, t-1}^{2}+\delta \sigma_{s, t-1}^{2}
$$

where $\varepsilon_{s, t} \equiv R_{s, t}-\bar{R}_{s}$. The GARCH(1,1) process for volatility in equation (14) is introduced by Bollerslev (1986) and contains an ARCH parameter $\alpha$ such that squared return shocks $\left(\varepsilon_{s, t-1}^{2}\right)$ affect the conditional variance estimate along with the GARCH parameter $\delta$ that captures the persistence of volatility observed in financial returns. We estimate the GARCH parameters for each specification using maximum likelihood estimation (MLE). In the second step, we regress excess returns on the conditional volatility estimates,

$$
R_{s, t}=\mu+\gamma_{s} \hat{\sigma}_{s, t}^{2}+\lambda R_{s, t-1}+\eta_{s, t}
$$

to assess the relation between conditional expected return and conditional variance. Equation (15) includes a lagged stock market return, $R_{s, t-1}$, as an additional explanatory variable for returns. As discussed in Section 4, nonsynchronicity is a potential concern for modeling portfolio returns. Including a lagged return allows last period's portfolio return to explain the portion of the current return that is attributable to nonsynchronous return measurement, but we also consider a version of this model with $\lambda$ constrained to equal zero.

To assess statistical significance with the two-step approach, we use a bootstrap procedure to 
produce finite-sample distributions of the test statistics in the second step. Specifically, we generate bootstrap standard errors and $p$-values from 100,000 resamples of 732 monthly observations. We use a pairs bootstrap approach that draws pairs of monthly stock returns and conditional variance estimates to account for heteroskedasticity in $\eta_{s, t}$. This procedure also allows us to formally test whether estimates of the risk-return coefficients from the stock-based tests are significantly biased relative to alternative unbiased estimates from Section 6 .

Panel A of Table 2 contains the results for the stock market portfolio. Consistent with prior literature, the GARCH parameter estimates indicate fairly persistent variance processes. The $\alpha$ estimate is 0.11 , and the $\delta$ parameter is 0.84 . The implied volatility half life for this specification is just under 15 months (measured as $\ln (0.5) / \ln (\alpha+\delta)$ ). For the second-stage regression in Case 1, the stock market has an estimated $\gamma_{s}$ of 3.10. Using the one-tailed test implied by the prediction $\gamma_{s}>0$, this estimate is marginally statistically significant with a $p$-value of 0.06 . The intercept term is also statistically indistinguishable from zero, which indicates that the fitted average return closely matches the average stock market return in the data. Including a lagged stock return in the model has relatively little effect on inferences, as the $\gamma_{s}$ estimate of 3.29 in Case 2 remains statistically significant ( $p$-value of 0.04). Thus, the empirical evidence in Panel A suggests that the expected return of stocks is positively related to stock market volatility.

We assess the magnitude of bias in the coefficient of relative risk aversion estimates from the stock-based tests with the expression from Section $3, \gamma_{s}=\rho \frac{\sigma_{a w}}{\sigma_{s}} \gamma$. Using the time series of excess returns for stocks and our aggregate wealth portfolio developed in Section 4, we estimate $\hat{\rho}=0.92$, $\hat{\sigma}_{a w}=1.94 \%$, and $\hat{\sigma}_{s}=4.35 \%$. Panel A of Table 2 reports bias-corrected estimates of the coefficient

of relative risk aversion, $\hat{\gamma}=\hat{\rho}^{-1} \frac{\hat{\sigma}_{s}}{\hat{\sigma}_{a w}} \hat{\gamma}_{s}$, based on these figures. The bias-corrected estimates are 7.60 and 8.07 for Cases 1 and 2, respectively, indicating that the risk-return coefficient estimated from stock-based tests understates the coefficient of relative risk aversion by almost $60 \%$.

\section{Estimating the Risk-Reward Coefficient}

In this section, we investigate alternative tests that are directly motivated by the ICAPM and yield unbiased $\gamma$ estimates conditional on our aggregate wealth proxy. Section 6.1 relates expected aggregate wealth returns to conditional aggregate wealth variance, Section 6.2 models expected stock market returns as a linear function of the conditional covariance between stocks and aggregate wealth, Section 6.3 relates expected returns of various asset classes to their conditional covariances with the aggregate wealth portfolio, and Section 6.4 examines the risk-return relation for stock 
portfolios sorted on size, book-to-market, and momentum. The tests in Sections 6.3 and 6.4 also allow us to assess how well the ICAPM works in explaining cross-sectional differences in average returns across assets.

Although each of the empirical specifications below produces unbiased estimates of the riskreturn coefficient, test power is unlikely to be substantially improved relative to the stock-based tests studied above as discussed in the Internet Appendix. These tests are thus primarily useful for drawing inferences about the economic quantity of interest $\gamma$. Several studies in the literature test the ICAPM using stocks as an aggregate wealth proxy and interpret the risk-return coefficient as an estimate of the coefficient of relative risk aversion, including Chou (1988), Ghysels, Santa-Clara, and Valkanov (2005), Bali and Peng (2006), Lundblad (2007), Pástor, Sinha, and Swaminathan (2008), Bollerslev, Osterrieder, Sizova, and Tauchen (2013), and Hedegaard and Hodrick (2016). Estimates of the coefficient of relative risk aversion from time-series studies with alternative designs may also be affected by the aggregate wealth proxy, including Chan, Karolyi, and Stulz (1992), Scruggs (1998), Scruggs and Glabadanidis (2003), Guo and Whitelaw (2006), Bali (2008), Bali and Engle (2010), Hedegaard and Hodrick (2014), and Rossi and Timmermann (2015). We thus contribute to the literature by producing new estimates of $\gamma$ using our more comprehensive aggregate wealth proxy.

\subsection{Variance Specification with Aggregate Wealth Returns}

Our first alternative method examines the ICAPM implication in equation (1) using time-series data on our aggregate wealth portfolio. In particular, we relate expected aggregate wealth returns to conditional aggregate wealth portfolio variance. These tests are designed analogously to the stock-based tests developed in Section 5, and the results are reported in Panel B of Table 2. The GARCH parameter estimates suggest that aggregate wealth variance is relatively persistent. The $\alpha$ parameter is 0.11 and the $\delta$ estimate is 0.82 , producing a volatility half life of about 10 months. Figure 2 plots the fitted conditional standard deviation for the stock market and aggregate wealth portfolios using the $\operatorname{GARCH}(1,1)$ specifications in Table 2, Consistent with the stylized facts on return variance, we observe volatility spikes for both market proxies followed by a tendency for volatility to drift downward. The portfolios tend to experience variance spikes in the same periods, but there is substantial variation across shocks in the relative responses of stocks versus aggregate wealth. For instance, the aggregate wealth portfolio experiences a larger volatility shock during the period of economic uncertainty in March 1980 than it does in October 1987, whereas the variance of 
the stock market is over twice as large after the 1987 crash compared to the spike in 1980. Overall, the variance dynamics of aggregate wealth and stocks are similar, but the ratio of the risk levels of the two portfolios varies substantially over time.

Turning to the return-regression parameters in Panel B of Table 2 , the $\gamma$ estimate in Case 3 is 7.52 , which is statistically significant with a one-tailed $p$-value of 0.05 . This estimate is noticeably larger than the corresponding stock-based estimate of 3.10 from Case 1. To form a statistical assessment of the bias associated with an improperly specified proxy for aggregate wealth, we also provide a bootstrap $p$-value for the one-sided test that the risk-return coefficient, $\gamma$, is less than the corresponding coefficient from stocks, $\gamma_{s}$. Although the difference in these coefficients is economically large, it is marginally insignificant with a $p$-value just above 0.10 . The intercept in Case 3 is statistically indistinguishable from zero, such that the ICAPM explains the level of the average aggregate wealth portfolio return. When a lagged return is introduced in Case 4, its coefficient is statistically significant and the regression $R^{2}$ increases from $0.48 \%$ to $3.68 \%$, indicating that controlling for nonsynchronous return measurement is important for the aggregate wealth portfolio. Inferences about the risk-return relation, however, are largely unchanged as the $\gamma$ coefficient estimate is 8.52 with a $p$-value of 0.03 . In this case, the estimated risk-return parameter is also significantly larger than the corresponding estimate from stocks in Case 2.

In summary, directly testing the ICAPM using our more broadly defined aggregate wealth portfolio produces evidence of a large and statistically significant relation between risk and return. In the Internet Appendix, we demonstrate the robustness of our stock-based tests in Section 5 and the aggregate wealth tests in this section to other approaches to estimating conditional return variance. Specifically, we consider the GARCH-M method that is popular in the literature (e.g., French, Schwert, and Stambaugh (1987), Baillie and DeGennaro (1990), and Lundblad (2007)). We also use two-step approaches in which the conditional variance of stock market or aggregate wealth returns is estimated using an EGARCH or fractionally integrated GARCH (FIGARCH) model.

\subsection{Covariance Specification with Stock Returns}

Our results to this point suggest that tests of the ICAPM that relate expected stock market returns to conditional stock market variance are misspecified. We can still implement stock-based tests of the ICAPM, however, based on the model's implication that expected stock returns are given by

$$
E_{t-1}\left(R_{s, t}\right)=\gamma \sigma_{s, a w, t} .
$$


Equation (16) shows that the conditional expected stock market return is proportional to the conditional covariance between stock returns and aggregate wealth returns with the coefficient of relative risk aversion determining the reward for risk.

This approach is similar in spirit to tests from several past studies. Bollerslev, Engle, and Wooldridge (1988) test the ICAPM by forecasting stock returns using the conditional covariance of stocks with a market portfolio that includes stocks, Treasury bills, and Treasury bonds. The aggregate wealth portfolio that we consider in this paper, however, is a much broader market proxy than the one introduced by Bollerslev, Engle, and Wooldridge (1988). Whereas stocks comprise approximately $80 \%$ of their market proxy, the average weight of corporate equity in our aggregate wealth portfolio is less than $20 \%$ as shown in Table 1. Another set of studies, including Harvey (1991), Chan, Karolyi, and Stulz (1992), Bekaert and Harvey (1995), and Pástor, Sinha, and Swaminathan (2008), relate expected U.S. stock market returns to either the conditional world stock market variance or the conditional covariance between U.S. and world stock market returns. We find that the alternative asset classes included in our aggregate wealth portfolio are important for inferences about risk and return.

We investigate the prediction in equation (16) using a two-step approach. In the first stage, we model the conditional variance-covariance matrix of aggregate wealth returns and stock returns using a diagonal BEKK bivariate GARCH model. In this model, the vector of demeaned excess returns, $\left[R_{a w, t}-\bar{R}_{a w} \quad R_{s, t}-\bar{R}_{s}\right]^{\prime}$, has a bivariate normal distribution with mean zero and variancecovariance matrix $\Sigma_{t}$. The conditional variance-covariance matrix evolves according to

$$
\Sigma_{t}=\Omega+\alpha\left(\varepsilon_{t-1} \varepsilon_{t-1}^{\prime}\right) \alpha+\delta \Sigma_{t-1} \delta
$$

where $\varepsilon_{t}$ is the vector of return innovations, $\Omega$ is a symmetric $2 \times 2$ matrix, and $\alpha$ and $\delta$ are $2 \times 2$ diagonal matrices with $\alpha=\operatorname{diag}\left(\alpha_{11}, \alpha_{22}\right)$ and $\delta=\operatorname{diag}\left(\delta_{11}, \delta_{22}\right)$. In the second stage, we regress stock market excess returns on the conditional covariance between stock returns and aggregate wealth returns,

$$
R_{s, t}=\mu+\gamma \hat{\sigma}_{s, a w, t}+\lambda R_{s, t-1}+\eta_{s, t}
$$

As in our prior tests, we estimate versions of the model in equation (18) that include or exclude the lagged excess stock market return as an explanatory variable. This two-step approach provides a test of the ICAPM based on expected stock returns that is free from the biases discussed in Section 3. 
The results are reported in Table 3. Panel A shows the first-stage MLE estimates for the diagonal BEKK bivariate GARCH model, and the GARCH parameter estimates continue to suggest persistence in the variance processes. Panel B presents estimates from the second-stage return regressions. In the specification without a lag of the dependent variable, the estimate of $\gamma$ is 7.16 ( $p$-value of 0.07). When the lagged excess stock market return is added to the model as an explanatory variable, the risk-return coefficient is slightly larger at 7.63 ( $p$-value of 0.05 ) and the regression $R^{2}$ improves modestly from $0.41 \%$ to $1.21 \%$. In each specification, the estimate of $\gamma$ is significantly larger than the corresponding biased coefficient based on stock variance from Panel A of Table 2. Most importantly, the $\gamma$ estimates from the stock-based tests of the ICAPM in Table 3 are very similar to those obtained in our tests from Table 2 , Panel B that use the aggregate wealth portfolio. The evidence thus suggests that systematic risk is priced similarly in stocks and aggregate wealth once we mitigate the biases associated with stock-based tests.

\subsection{Covariance Specification with a Cross Section of Asset-Class Returns}

Our final two sets of tests for assessing the risk-return relation build on the covariance approach introduced in Section 6.2. In particular, we note that the ICAPM implication,

$$
E_{t-1}\left(R_{j, t}\right)=\gamma \sigma_{j, a w, t}
$$

applies to any asset $j$. We can thus test this model prediction for broad cross sections of asset returns, and we consider several interesting alternatives below. In this section, we focus specifically on the ability of the ICAPM to explain average returns across the component asset classes of our aggregate wealth portfolio.

The aggregate wealth proxy developed in Section 4 is based on nine component return series. Deposits earn the risk-free rate each month such that the expected excess return and conditional covariance for this asset class are always zero. We therefore test equation (19) using the remaining eight asset classes. We also include the aggregate wealth portfolio itself as an additional asset. This cross-sectional approach is similar to studies by Bali (2008) and Bali and Engle (2010), which relate the returns of several portfolios to their conditional covariances with the stock market portfolio using dynamic conditional correlation (DCC) methods.

For each individual asset class, we use a diagonal BEKK bivariate GARCH model to estimate the conditional covariance $\sigma_{j, a w, t}$ following equation $(17)$. We also use the $\operatorname{GARCH}(1,1)$ model from Panel B of Table 2 to measure aggregate wealth portfolio variance. Based on these estimates, 
we specify the model

$$
R_{j, t}=\mu_{j}+\gamma \hat{\sigma}_{j, a w, t}+\lambda_{j} R_{j, t-1}+\eta_{j, t}
$$

which allows for asset-class-specific intercepts, $\mu_{j}$, but constrains $\gamma$ to be equal across assets. We estimate equation (20) using a pooled OLS regression with asset-class fixed effects. Note that because the returns data for agency debt and municipal debt are not available for the full sample period, an unbalanced panel is used to estimate the model.

We estimate standard errors for the pooled OLS regressions using a bootstrap procedure similar to the one outlined in Section 5. In constructing the 100,000 bootstrap samples, we attempt to retain the unbalanced structure of the original data resulting from shorter data samples for agency debt and municipal debt. Specifically, each bootstrap sample includes 732 monthly resamples from the original data (i.e., a monthly return and variance for the aggregate wealth portfolio and a monthly return and covariance for each asset class) with 300 observations resampled from the period 1953 to 1977, 132 observations resampled from the period 1978 to 1988, and 300 observations resampled from the period 1989 to 2013. An important byproduct of this bootstrap design is that we are able to account for contemporaneous cross-correlations and time-series heteroskedasticity in $\eta_{j, t}$ in our statistical inference.

Table 4 shows results from testing the ICAPM among component asset classes and the aggregate wealth portfolio. Panel A summarizes the diagonal BEKK GARCH parameters for each asset class and presents the estimated intercepts from equation 20. Panel B provides additional details for the second-stage regressions. The estimates of $\gamma$ are 7.32 and 7.53 in the specifications that omit and include a lag of the dependent variable, respectively. These coefficients are similar in magnitude to those from alternative tests in Panel B of Table 2 and Table 3 . The risk-return coefficients are also statistically significant with bootstrap $p$-values of 0.04 and 0.03 . Several intercepts in the models are, however, significantly different from zero, which indicates that the expected returns of some asset classes are not fully explained by their respective covariances with aggregate wealth.

Finally, for each case we test the hypothesis that the intercepts in equation (20) are jointly equal to zero. We use a double bootstrap approach (e.g., MacKinnon (2009)) that is designed to account for cross-correlations and time-series heteroskedasticity in asset returns as well as heteroskedasticity across asset classes. Our bootstrap method determines the likelihood of observing the minimum of the bootstrap $p$-values across the nine intercepts under the null hypothesis that the intercepts are jointly equal to zero. We first generate 10,000 bootstrap samples that conform to the null. Specifically, we impose $\mu_{j}=0$ for all $j$ by resampling monthly adjusted returns and conditional 
covariances for each asset class, where the adjusted return for asset $j$ is given by $R_{j, t}^{*}=R_{j, t}-\hat{\mu}_{j}$. For each of the 10,000 first-level bootstrap samples, we find the two-tailed bootstrap $p$-values for the nine intercepts by employing a pairs bootstrap approach with 10,000 second-level bootstrap samples. Finally, we calculate the percentage of bootstrap samples that produce a minimum $p$-value across the intercepts that is smaller than the actual minimum $p$-value from the data. The $p$-value for this test reported in Panel B of Table 4 thus represents the probability that we would observe a more extreme minimum bootstrap $p$-value from the data if the intercepts are jointly equal to zero. The null hypothesis is rejected at the $5 \%$ significance level in Case 1, but not rejected in Case 2. As such, average asset-class returns in the second specification appear more in line with the ICAPM.

\subsection{Covariance Specification with a Cross Section of Anomaly Portfolio Returns}

In this section, we apply the model from Section 6.3 to assess the ICAPM using portfolios sorted on well-know anomaly variables (i.e., size, book-to-market equity, and prior stock returns). These tests also allow us to obtain unbiased estimates of $\gamma$, but our primary focus in this section is on understanding the broader asset pricing implications of a more comprehensive aggregate wealth proxy. In particular, we compare the ICAPM's performance in explaining average return spreads across size, book-to-market, and momentum portfolios under the following two specifications for the market portfolio: (i) stocks and (ii) our aggregate wealth series.

We obtain data on returns for value-weighted decile portfolios sorted on size, book-to-market, and momentum from Kenneth French's website. We convert these returns to excess returns by subtracting the 30-day Government Bond index return. For each combination of market proxy (i.e., stocks or aggregate wealth) and set of decile portfolios (i.e., size, book-to-market, or momentum portfolios), we first estimate conditional covariances for each portfolio using the diagonal BEKK bivariate GARCH model in equation (17). We then estimate the model in equation 20 using panel data on returns and conditional covariances for the given combination of market proxy and test assets.

Panel A of Table 5 presents intercepts from the second stage return regressions for the top decile and bottom decile portfolios and their difference. In each model, "decile 1" corresponds to the portfolio with lower expected abnormal returns based on prior literature, i.e., large-cap stocks, growth stocks, or stocks with lower returns over the prior 12 months. Cases 1-6 are ICAPM regressions using conditional covariances with stock market returns as the explanatory variable, and Cases 7-12 represent the corresponding models with aggregate wealth as the market proxy. 
The results for Cases 1-2 and 7-8 in Table 5 suggest that the ICAPM does a reasonable job of explaining average returns across size portfolios, regardless of the market proxy. The abnormal return spreads for small stocks relative to big stocks range from $-0.25 \%$ to $0.15 \%$ per month, and none of the four estimates is statistically significant. In contrast, using a broader measure of aggregate wealth seems to improve the ICAPM's ability to account for return spreads related to book-to-market ratios. In Case 3, a strategy that takes a long position in value stocks and a short position in growth stocks earns an abnormal return of $0.38 \%$ per month (bootstrap $p$-value of 0.01) relative to the ICAPM with stocks as the market proxy. Introducing our broader definition of aggregate wealth in Case 9 accounts for $26 \%$ of this difference in abnormal return, and the resulting estimate of $0.28 \%$ is only marginally significant ( $p$-value of 0.06 ). Similarly, the long-short portfolio abnormal return is reduced by $38 \%$ in magnitude moving from Case 4 to Case 10 . The difference in intercepts for value and growth stocks of just $0.17 \%$ per month is also statistically insignificant ( $p$-value of 0.17 ) in the specification with the broader market proxy in Case 10. Finally, Panel A of Table 5 suggests that neither market proxy does well in explaining differences in performance across momentum-sorted portfolios. The high-minus-low decile spreads range from $1.25 \%$ to $1.49 \%$ per month in Cases 5-6 and 11-12, and all four bootstrap p-values are 0.00.

Panel B of Table 5 presents additional details for the panel regressions. The estimates of $\gamma$ from the models using aggregate wealth as the market proxy (i.e., Cases 7-12) range from 7.59 to 9.29 and are noticeably larger than the corresponding figures from stock-based tests in Cases 1-6. Importantly, these estimates based on covariances of anomaly portfolio returns with aggregate wealth returns are in line with our other unbiased estimates in Tables 2, 4 . Regardless of the market proxy, the null hypothesis that the intercepts are jointly equal to zero is not rejected for portfolios formed on size or book-to-market. In contrast, the null is rejected at the $10 \%$ level for the momentum portfolios in each case.

Our tests in this section confirm that the specification of aggregate wealth has additional asset pricing implications, particularly for our understanding of the book-to-market anomaly. In the Internet Appendix, we report supplementary asset pricing results using our aggregate wealth portfolio. In particular, we estimate standard time-series regression alphas for the anomaly portfolios relative to the CAPM and Fama-French (1993) three-factor model using alternative proxies (i.e., stocks and aggregate wealth) for the market factor. We also examine standard cross-sectional asset pricing tests to highlight the importance of the market proxy in explaining average returns on anomaly portfolios and industry portfolios. 


\section{Conclusion}

Whereas prior studies examine the risk-return relation in the stock market and find mixed results, we show that the accuracy of the market proxy matters in tests of the ICAPM. Because stocks are an imperfect aggregate wealth proxy, the risk-return coefficient in stock-based tests is a downward-biased estimate of the coefficient of relative risk aversion. This weakened relation also reduces the power of risk-return tests, which helps to explain the difficulty of establishing a robust positive relation between risk and return in stocks.

Using a more comprehensive aggregate wealth proxy, we produce evidence of a large, positive reward for risk in line with ICAPM predictions. We obtain $\gamma$ estimates around seven to nine from a variety of tests, such that the empirical risk-return results are indicative of high risk aversion for the representative investor compared to findings in the economics literature. In particular, Arrow (1971) argues that $\gamma$ close to one is economically reasonable, and estimates of the coefficient of relative risk aversion have often been in the neighborhood of one in economics studies (e.g., Holt and Laury (2002), Chetty (2006), and Andersen, Harrison, Lau, and Rutström (2008)). In contrast, our $\gamma$ estimates are generally in line with many estimates of risk aversion that use financial data for estimation (e.g., Kandel and Stambaugh (1991), Aït-Sahalia and Lo (2000), Vissing-Jørgensen and Attanasio (2003), Bliss and Panigirtzoglou (2004), and Malloy, Moskowitz, and Vissing-Jørgensen (2009)). Our study thus adds to the evidence in the literature that asset prices reflect relatively high levels of risk aversion.

\section{SUPPLEMENTARY MATERIAL}

Internet Appendix: This file contains analytical results and Monte Carlo simulations characteriz-

ing the bias and power properties of stock-based tests of the ICAPM, additional detail on aggregate wealth portfolio component weights and returns, analysis of measurement error in aggregate wealth returns, and supplementary empirical tests. (pdf file) 


\section{References}

Aït-Sahalia, Yacine, and Andrew W. Lo, 2000, Nonparametric risk management and implied risk aversion, Journal of Econometrics 94, 9-51.

Andersen, Steffen, Glenn W. Harrison, Morten I. Lau, and E. Elisabet Rutström, 2008, Eliciting risk and time preferences, Econometrica 76, 583-618.

Arrow, Kenneth J., 1971, Essays in the Theory of Risk Bearing. North Holland, Amsterdam.

Baillie, Richard T., and Ramon P. DeGennaro, 1990, Stock returns and volatility, Journal of Financial and Quantitative Analysis 25, 203-214.

Bali, Turan G., 2008, The intertemporal relation between expected returns and risk, Journal of Financial Economics 87, 101-131.

Bali, Turan G., Nusret Cakici, Xuemin (Sterling) Yan, and Zhe Zhang, 2005, Does idiosyncratic risk really matter?, Journal of Finance 60, 905-929.

Bali, Turan G., and Robert F. Engle, 2010, The intertemporal capital asset pricing model with dynamic conditional correlations, Journal of Monetary Economics 57, 377-390.

Bali, Turan G., and Lin Peng, 2006, Is there a risk-return trade-off? Evidence from high-frequency data, Journal of Applied Economics 21, 1169-1198.

Bekaert, Geert, and Campbell R. Harvey, 1995, Time-varying world market integration, Journal of Finance 50, 339-350.

Bekaert, Geert, and Marie Hoerova, 2014, The VIX, the variance premium, and stock market volatility, Journal of Econometrics 183, 181-192.

Black, Fischer, 1989, Should you use stocks to hedge your pension liability?, Financial Analysts Journal 45, 10-12.

Bliss, Robert R., and Nikolaos Panigirtzoglou, 2004, Option-implied risk aversion estimates, Journal of Finance 59, 407-446.

Bollerslev, Tim, 1986, Generalized autoregressive conditional heteroskedasticity, Journal of Econometrics 31, 307-327.

Bollerslev, Tim, Robert F. Engle, and Jeffrey M. Wooldridge, 1988, A capital asset pricing model with time-varying covariances, Journal of Political Economy 96, 116-131.

Bollerslev, Tim, Daniela Osterrieder, Natalia Sizova, and George Tauchen, 2013, Risk and return: Long-run relations, fractional cointegration, and return predictability, Journal of Financial Economics 108, 409-424.

Bollerslev, Tim, George Tauchen, and Hao Zhou, 2009, Expected stock returns and variance risk premia, Review of Financial Studies 22, 4463-4492.

Bollerslev, Tim, and Hao Zhou, 2006, Volatility puzzles: A simple framework for gauging returnvolatility regressions, Journal of Econometrics 131, 123-150.

Brandt, Michael W., and Qiang Kang, 2004, On the relationship between the conditional mean and volatility of stock returns: A latent VAR approach, Journal of Financial Economics 72, 217-257. 
Brav, Alon, and Paul A. Gompers, 1997, Myth or reality? The long-run underpeformance of initial public offerings: Evidence from venture and nonventure capital-backed companies, Journal of Finance 52, 1791-1821.

Campbell, John Y., 1987, Stock returns and the term structure, Journal of Financial Economics 18, 373-399.

Campbell, John Y., Stefano Giglio, Christopher Polk, and Robert Turley, 2017, An intertemporal CAPM with stochastic volatility, Forthcoming in Journal of Financial Economics.

Campbell, John Y., and Ludger Hentschel, 1992, No news is good news: An asymmetric model of changing volatility in stock returns, Journal of Financial Economics 31, 281-318.

Chan, K.C., G. Andrew Karolyi, and René M. Stulz, 1992, Global financial markets and the risk premium on U.S. equity, Journal of Financial Economics 32, 137-167.

Chetty, Raj, 2006, A new method for estimating risk aversion, American Economic Review 96, $1821-1834$.

Chou, Ray Yeutien, 1988, Volatility persistence and stock valuations: Some empirical evidence using GARCH, Journal of Applied Economics 3, 279-294.

Cochrane, John H., 2005, The risk and return of venture capital, Journal of Financial Economics $75,3-52$.

Engle, Robert, and Kenneth F. Kroner, 1995, Multivariate simultaneous GARCH, Econometric Theory 11, 122-150.

Fama, Eugene F., and Kenneth R. French, 1993, Common risk factors in the returns on bonds and stocks, Journal of Financial Economics 33, 3-53.

French, Kenneth R., G. William Schwert, and Robert F. Stambaugh, 1987, Expected stock returns and volatility, Journal of Financial Economics 19, 3-29.

Ghysels, Eric, Pedro Santa-Clara, and Rossen Valkanov, 2005, There is a risk-return trade-off after all, Journal of Financial Economics 76, 509-548.

Glosten, Lawrence R., Ravi Jagannathan, and David E. Runkle, 1993, On the relation between the expected value and the volatility of the nominal excess return on stocks, Journal of Finance 48, $1779-1801$.

Goyal, Amit, and Pedro Santa-Clara, 2003, Idiosyncratic risk matters!, Journal of Finance 58, 975-1008.

Guo, Hui, and Robert Savickas, 2006, Idiosyncratic volatility, stock market volatility, and expected stock returns, Journal of Business and Economic Statistics 24, 43-56.

Guo, Hui, and Robert F. Whitelaw, 2006, Uncovering the risk-return relation in the stock market, Journal of Finance 61, 1433-1463.

Harrison, Paul, and Harold H. Zhang, 1999, An investigation of the risk and return relation at long horizons, Review of Economics and Statistics 81, 399-408.

Harvey, Campbell R., 1991, The world price of covariance risk, Journal of Finance 46, 111-157. 
— , 2001, The specification of conditional expectations, Journal of Empirical Finance 8, 573637.

Hedegaard, Esben, and Robert J. Hodrick, 2014, Measuring the risk-return tradeoff with timevarying conditional covariances, Working Paper, Arizona State University.

— , 2016, Estimating the risk-return trade-off with overlapping data inference, Journal of Banking and Finance 67, 135-145.

Holt, Charles A., and Susan K. Laury, 2002, Risk aversion and incentive effects, American Economic Review 92, 1644-1655.

Kandel, Shmuel, and Robert F. Stambaugh, 1987, On correlations and inferences about meanvariance efficiency, Journal of Financial Economics 18, 61-91.

— 1991, Asset returns and intertemporal preferences, Journal of Monetary Economics 27, 39-71.

Lettau, Martin, and Sydney C. Ludvigson, 2010, Measuring and modeling variation in the riskreturn trade-off, in Yacine Ait-Sahalia, and Lars P. Hansen, eds.: Handbook of Financial Econometrics (Elsevier).

Lo, Andrew W., and A. Craig MacKinlay, 1990, An econometric analysis of nonsynchronous trading, Journal of Econometrics 45, 181-211.

Ludvigson, Sydney C., and Serena Ng, 2007, The empirical risk-return relation: A factor analysis approach, Journal of Financial Economics 83, 171-222.

Lundblad, Christian, 2007, The risk return tradeoff in the long run: 1836-2003, Journal of Financial Economics 85, 123-150.

Lustig, Hanno, Stijn Van Nieuwerburgh, and Adrien Verdelhan, 2013, The wealth-consumption ratio, Review of Asset Pricing Studies 3, 38-94.

MacKinnon, James G., 2009, Bootstrap hypothesis testing, in David A. Belsley, and Erricos John Kontoghiorghes, eds.: Handbook of Computational Econometrics (John Wiley and Sons).

Malloy, Christopher J., Tobias J. Moskowitz, and Annette Vissing-Jørgensen, 2009, Long-run stockholder consumption risk and asset returns, Journal of Finance 64, 2427-2479.

Merton, Robert C., 1973, An intertemporal capital asset pricing model, Econometrica 41, 867-887.

— , 1980, On estimating the expected return on the market: An exploratory investigation, Journal of Financial Economics 8, 323-361.

Nelson, Daniel B., 1991, Conditional heteroskedasticity in asset returns: A new approach, Econometrica 59, 347-370.

Novy-Marx, Robert, and Joshua Rauh, 2011, Public pension promises: How big are they and what are they worth?, Journal of Finance 66, 1211-1249.

Pástor, Ľuboš, Meenakshi Sinha, and Bhaskaran Swaminathan, 2008, Estimating the intertemporal risk-return tradeoff using the implied cost of capital, Journal of Finance 63, 2859-2897. 
Poterba, James, Joshua Rauh, Steven Venti, and David Wise, 2007, Defined contribution plans, defined benefit plans, and the accumulation of returement wealth, Journal of Public Economics 91, 2062-2086.

Roll, Richard, 1977, A critique of the asset pricing theory's tests - Part I: On past and potential testability of the theory, Journal of Financial Economics 4, 129-176.

Rossi, Alberto, and Allan Timmermann, 2015, Modeling covariance risk in Merton's ICAPM, Review of Financial Studies 28, 1428-1461.

Scruggs, John T., 1998, Resolving the puzzling intertemporal relation between the market risk premium and conditional market variance: A two-factor approach, Journal of Finance 53, 575603.

Scruggs, John T., and Paskalis Glabadanidis, 2003, Risk premia and the dynamic covariance between stock and bond returns, Journal of Financial and Quantitative Analysis 38, 295-316.

Shanken, Jay, 1987, Multivariate proxies and asset pricing relations: Living with the Roll critique, Journal of Financial Economics 18, 91-110.

Stambaugh, Robert F., 1982, On the exclusion of assets from tests of the two-parameter model: A sensitivity analysis, Journal of Financial Economics 10, 237-268.

Turner, Christopher M., Richard Startz, and Charles R. Nelson, 1989, A Markov model of heteroskedasticity, risk, and learning in the stock market, Journal of Financial Economics 25, 3-22.

Vissing-Jørgensen, Annette, and Orazio P. Attanasio, 2003, Stock-market participation, intertemporal substitution, and risk-aversion, American Economic Review 93, 383-391.

Whitelaw, Robert F., 1994, Time variations and covariations in the expectation and volatility of stock market returns, Journal of Finance 49, 515-541. 


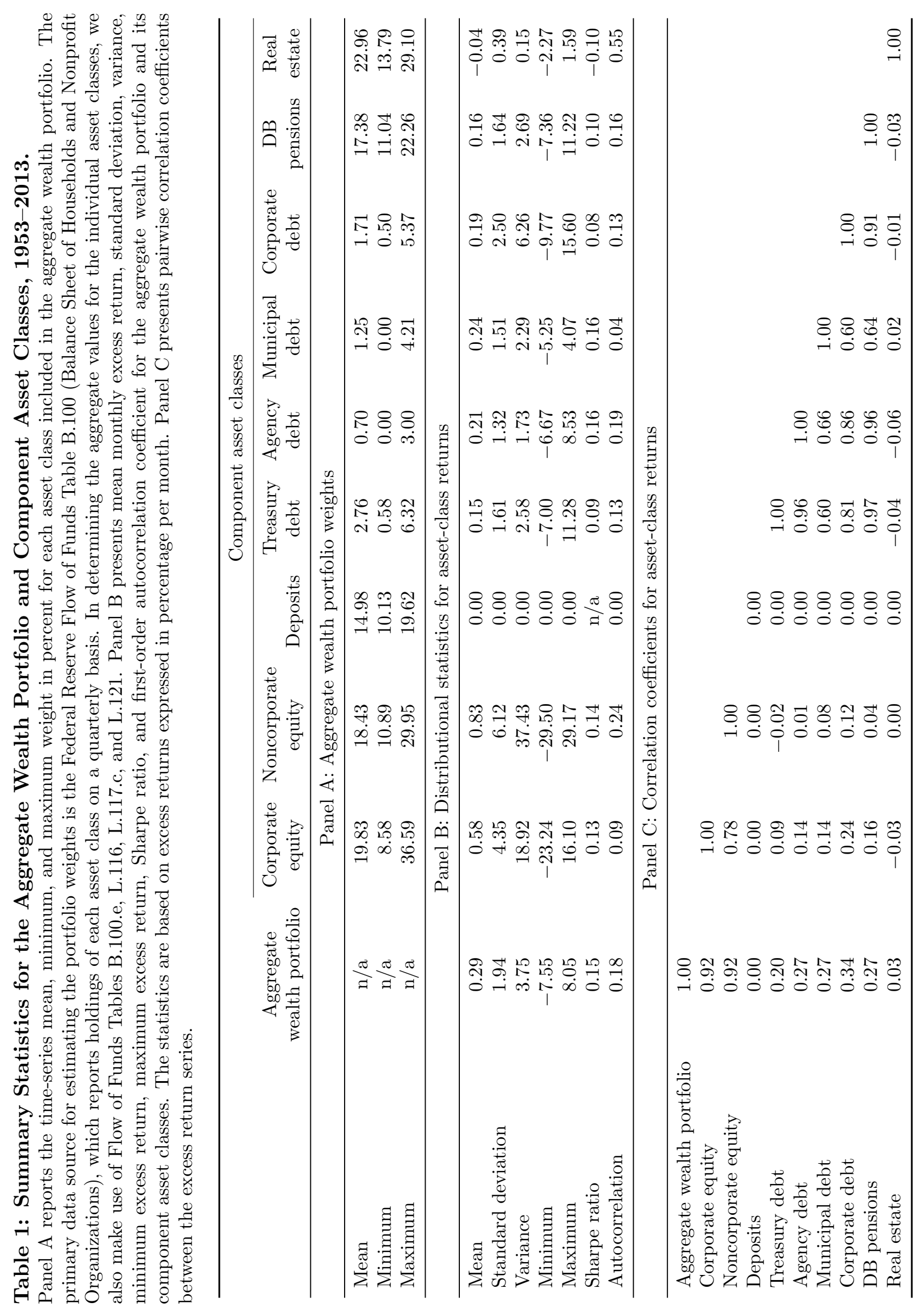




\section{Table 2: The Risk-Return Tradeoff for the Stock Market Portfolio and Aggregate}

Wealth Portfolio, 1953-2013.

The table presents evidence on the relation between excess return and volatility for the stock market portfolio (Panel A) and the aggregate wealth portfolio (Panel B) using a two-step estimation approach. For each portfolio, we estimate first-stage $\operatorname{GARCH}(1,1)$ model parameters using maximum likelihood estimation (MLE). We assume that the demeaned excess return in month $t$ for market portfolio $i, R_{i, t}-\bar{R}_{i}$, is normally distributed with mean zero and variance $\sigma_{i, t}^{2}$. The conditional variance evolves according to a GARCH $(1,1)$ process, $\sigma_{i, t}^{2}=\omega+\alpha \varepsilon_{i, t-1}^{2}+\delta \sigma_{i, t-1}^{2}$. The second-stage return regression for stocks (aggregate wealth) is given by $R_{s, t}=\mu+\gamma_{s} \hat{\sigma}_{s, t}^{2}+\lambda R_{s, t-1}+\eta_{s, t}\left(R_{a w, t}=\mu+\gamma \hat{\sigma}_{a w, t}^{2}+\lambda R_{a w, t-1}+\eta_{a w, t}\right)$. For these regressions, we report bootstrap standard errors in parentheses and a bootstrap $p$-value for the one-sided test of the null hypothesis that the risk-return parameter is less than zero in brackets. The $R^{2}$ value in each case is the second-stage regression $R^{2}$. For each estimate of $\gamma_{s}$ in Panel A, we report a bias-corrected estimate of the true risk-return coefficient, $\hat{\gamma}=\hat{\rho}^{-1} \frac{\hat{\sigma}_{s}}{\hat{\sigma}_{a w}} \hat{\gamma}_{s}$, where $\hat{\sigma}_{s}$ and $\hat{\sigma}_{a w}$ are the unconditional standard deviations of the stock market and aggregate wealth portfolios, respectively, and $\hat{\rho}$ is the correlation between the excess returns on stocks and aggregate wealth. In Panel $\mathrm{B}$, each bootstrap $p$-value, $p\left(\gamma \leq \gamma_{s}\right)$, corresponds to a one-sided test that the risk-return coefficient is less than the corresponding risk-return coefficient estimated from stocks. The standard errors and $p$-values for the bias-corrected estimates in Panel A and the $p$-values for the difference in coefficients in Panel B are based on bootstrap resamples from the joint empirical distribution of the monthly stock market return, aggregate wealth return, conditional stock market variance, and conditional aggregate wealth variance.

\begin{tabular}{|c|c|c|c|c|c|c|c|c|}
\hline \multicolumn{9}{|c|}{ Panel A: Stock market portfolio } \\
\hline \multirow[b]{2}{*}{ Case } & \multicolumn{3}{|c|}{$\begin{array}{c}\text { First-stage } \\
\operatorname{GARCH}(1,1) \text { parameters }\end{array}$} & \multicolumn{4}{|c|}{$\begin{array}{l}\text { Second-stage } \\
\text { return regression parameters }\end{array}$} & \multirow{2}{*}{$\begin{array}{c}\begin{array}{c}\text { Bias-corrected } \\
\text { estimate }\end{array} \\
\gamma=\rho^{-1} \frac{\sigma_{s}}{\sigma_{a w}} \gamma_{s}\end{array}$} \\
\hline & $\omega \times 10^{4}$ & $\alpha$ & $\delta$ & $\mu \times 10^{2}$ & $\gamma_{s}$ & $\lambda$ & $R^{2}(\%)$ & \\
\hline (1) & $\begin{array}{c}0.976 \\
(0.373)\end{array}$ & $\begin{array}{c}0.115 \\
(0.027)\end{array}$ & $\begin{array}{c}0.839 \\
(0.031)\end{array}$ & $\begin{array}{c}-0.028 \\
(0.376)\end{array}$ & $\begin{array}{l}3.098 \\
(1.975)\end{array}$ & & 0.54 & $\begin{array}{c}7.603 \\
(4.843)\end{array}$ \\
\hline$(2)$ & & & & $\begin{array}{r}-0.116 \\
(0.361)\end{array}$ & $\begin{array}{c}{[0.058]} \\
3.288 \\
(1.890) \\
{[0.038]}\end{array}$ & $\begin{array}{c}0.090 \\
(0.045)\end{array}$ & 1.36 & $\begin{array}{l}{[0.058]} \\
8.068 \\
(4.635) \\
{[0.038]}\end{array}$ \\
\hline \multicolumn{9}{|c|}{ Panel B: Aggregate wealth portfolio } \\
\hline & \multicolumn{3}{|c|}{$\begin{array}{c}\text { First-stage } \\
\operatorname{GARCH}(1,1) \text { parameters }\end{array}$} & \multicolumn{4}{|c|}{$\begin{array}{c}\text { Second-stage } \\
\text { return regression parameters }\end{array}$} & $\begin{array}{l}\text { Test for difference } \\
\text { in coefficients }\end{array}$ \\
\hline Case & $\omega \times 10^{4}$ & $\alpha$ & $\delta$ & $\mu \times 10^{2}$ & $\gamma$ & $\lambda$ & $R^{2}(\%)$ & $p\left(\gamma \leq \gamma_{s}\right)$ \\
\hline$(3)$ & $\begin{array}{c}0.262 \\
(0.087)\end{array}$ & $\begin{array}{c}0.109 \\
(0.026)\end{array}$ & $\begin{array}{c}0.824 \\
(0.039)\end{array}$ & $\begin{array}{c}0.005 \\
(0.169)\end{array}$ & $\begin{array}{c}7.522 \\
(4.599) \\
{[0.053]}\end{array}$ & & 0.48 & 0.104 \\
\hline (4) & & & & $\begin{array}{r}-0.087 \\
(0.163)\end{array}$ & $\begin{array}{c}8.523 \\
(4.435) \\
{[0.028]}\end{array}$ & $\begin{array}{c}0.179 \\
(0.042)\end{array}$ & 3.68 & 0.066 \\
\hline
\end{tabular}


Table 3: The Risk-Return Tradeoff for the Stock Market Portfolio: Covariance Approach, 1953-2013.

The table presents evidence on the relation between stock market portfolio return and conditional covariance between stock returns and aggregate wealth returns using a two-step estimation approach. Panel A reports parameter estimates from a diagonal BEKK bivariate GARCH model. We estimate model parameters using the demeaned bivariate excess return series for the aggregate wealth portfolio and the stock market portfolio. We assume that the vector of demeaned excess returns in month $t,\left[\begin{array}{ll}R_{a w, t}-\bar{R}_{a w} & R_{s, t}-\bar{R}_{s}\end{array}\right]^{\prime}$, has a bivariate normal distribution with mean zero and variance-covariance matrix $\Sigma_{t}$. The conditional variance-covariance matrix evolves according to $\Sigma_{t}=\Omega+\alpha\left(\varepsilon_{t-1} \varepsilon_{t-1}^{\prime}\right) \alpha+\delta \Sigma_{t-1} \delta$, where $\Omega$ is a symmetric $2 \times 2$ matrix and $\alpha$ and $\delta$ are $2 \times 2$ diagonal matrices with $\alpha=\operatorname{diag}\left(\alpha_{11}, \alpha_{22}\right)$ and $\delta=\operatorname{diag}\left(\delta_{11}, \delta_{22}\right)$. We estimate the BEKK GARCH parameters using maximum likelihood estimation (MLE), and standard errors are shown in parentheses. Panel B reports results from the following second-stage regression of stock market excess return on the conditional covariance between stock returns and aggregate wealth returns and lagged excess stock return: $R_{s, t}=\mu+\gamma \hat{\sigma}_{s, a w, t}+\lambda R_{s, t-1}+\eta_{s, t}$. For the second-stage regressions, we report bootstrap standard errors in parentheses and a bootstrap $p$-value for the one-sided test of the null hypothesis that $\gamma \leq 0$ in brackets. The $R^{2}$ value in each case is the second-stage regression $R^{2}$. In Panel $\mathrm{B}$, each bootstrap $p$-value, $p\left(\gamma \leq \gamma_{s}\right)$, corresponds to a one-sided test that the risk-return coefficient is less than the corresponding risk-return coefficient estimated from stocks in Panel A of Table 2. These $p$-values are based on bootstrap resamples from the joint empirical distribution of the monthly stock market return, conditional stock market variance, and conditional covariance between stocks and aggregate wealth.

\begin{tabular}{|c|c|c|c|c|c|}
\hline \multicolumn{6}{|c|}{ Panel A: Diagonal BEKK GARCH model } \\
\hline & & \multicolumn{2}{|c|}{$\Omega \times 10^{4}$} & \multirow[b]{2}{*}{$\alpha_{i i}$} & \multirow[b]{2}{*}{$\delta_{i i}$} \\
\hline & & $\begin{array}{l}\text { Aggregate } \\
\text { wealth port. }\end{array}$ & $\begin{array}{l}\text { Corporate } \\
\text { equity }\end{array}$ & & \\
\hline \multicolumn{2}{|c|}{ Aggregate wealth port. } & $\begin{array}{c}0.117 \\
(0.039)\end{array}$ & $\begin{array}{c}0.279 \\
(0.089)\end{array}$ & $\begin{array}{c}0.284 \\
(0.036)\end{array}$ & $\begin{array}{c}0.945 \\
(0.013)\end{array}$ \\
\hline \multicolumn{2}{|c|}{ Corporate equity } & $\begin{array}{c}0.279 \\
(0.089)\end{array}$ & $\begin{array}{c}0.740 \\
(0.253)\end{array}$ & $\begin{array}{c}0.318 \\
(0.037)\end{array}$ & $\begin{array}{c}0.931 \\
(0.015)\end{array}$ \\
\hline \multicolumn{6}{|c|}{ Panel B: Second-stage return regressions } \\
\hline & \multicolumn{4}{|c|}{$\begin{array}{c}\text { Second-stage } \\
\text { return regression parameters }\end{array}$} & $\begin{array}{l}\text { Test for difference } \\
\text { in coefficients }\end{array}$ \\
\hline Case & $\mu \times 10^{2}$ & $\gamma$ & $\lambda$ & $R^{2}(\%)$ & $p\left(\gamma \leq \gamma_{s}\right)$ \\
\hline (1) & $\begin{array}{c}-0.001 \\
(0.379)\end{array}$ & $\begin{array}{c}7.161 \\
(4.816) \\
{[0.070]}\end{array}$ & & 0.41 & 0.093 \\
\hline (2) & $\begin{array}{r}-0.090 \\
(0.368)\end{array}$ & $\begin{array}{c}7.628 \\
(4.636) \\
{[0.051]}\end{array}$ & $\begin{array}{c}0.090 \\
(0.045)\end{array}$ & 1.21 & 0.072 \\
\hline
\end{tabular}


Table 4: The Risk-Return Tradeoff Across Asset Classes: Covariance Approach, 19532013.

The table presents evidence on the risk-return relation across asset classes using a two-step estimation approach. Panel A reports parameter estimates from diagonal BEKK bivariate GARCH models based on the demeaned bivariate excess return series for the aggregate wealth portfolio and each asset class. We estimate the BEKK GARCH parameters using maximum likelihood estimation (MLE), and standard errors are shown in parentheses. We also estimate the conditional variance for the aggregate wealth portfolio using the GARCH(1,1) model in Panel B of Table 2. In the second stage, we run the following regression of excess returns for individual asset classes and the aggregate wealth portfolio on the conditional covariance between asset-class returns and aggregate wealth returns and lagged excess returns: $R_{j, t}=\mu_{j}+\gamma \hat{\sigma}_{j, a w, t}+\lambda_{j} R_{j, t-1}+$ $\eta_{j, t}$. In Panel $\mathrm{A}$, we report intercepts for each asset class, and the corresponding bootstrap standard errors are shown in parentheses. For each model, Panel B provides a bootstrap $p$-value, $p\left(\mu_{1}=\cdots=\mu_{9}=0\right)$, for a test of the null hypothesis that the intercepts are jointly equal to zero. Panel B also presents an estimate of the risk-reward coefficient, $\gamma$, for each model with the corresponding bootstrap standard error in parentheses. A bootstrap $p$-value for the one-sided test of the null hypothesis that $\gamma \leq 0$ is given in brackets. The $R^{2}$ value in each case is the second-stage regression $R^{2}$.

\begin{tabular}{|c|c|c|c|c|c|c|c|c|c|}
\hline \multirow[b]{3}{*}{ Asset class } & \multicolumn{7}{|c|}{ Diagonal BEKK GARCH parameters } & \multirow{2}{*}{\multicolumn{2}{|c|}{$\begin{array}{c}\begin{array}{c}\text { Regression } \\
\text { intercepts }\end{array} \\
\mu_{j} \times 10^{2} \\
\end{array}$}} \\
\hline & \multicolumn{3}{|c|}{$\Omega \times 10^{4}$} & \multicolumn{2}{|c|}{$\alpha$} & \multicolumn{2}{|c|}{$\delta$} & & \\
\hline & $\Omega_{11}$ & $\Omega_{12}$ & $\Omega_{22}$ & $\alpha_{11}$ & $\alpha_{22}$ & $\delta_{11}$ & $\delta_{22}$ & Case (1) & Case $(2)$ \\
\hline Corp. equity & $\begin{array}{c}0.117 \\
(0.039)\end{array}$ & $\begin{array}{c}0.279 \\
(0.089)\end{array}$ & $\begin{array}{c}0.740 \\
(0.253)\end{array}$ & $\begin{array}{c}0.284 \\
(0.036)\end{array}$ & $\begin{array}{c}0.318 \\
(0.037)\end{array}$ & $\begin{array}{c}0.945 \\
(0.013)\end{array}$ & $\begin{array}{c}0.931 \\
(0.015)\end{array}$ & $\begin{array}{c}-0.013 \\
(0.328)\end{array}$ & $\begin{array}{c}-0.082 \\
(0.321)\end{array}$ \\
\hline Noncorp. equity & $\begin{array}{c}0.163 \\
(0.060)\end{array}$ & $\begin{array}{c}0.427 \\
(0.165)\end{array}$ & $\begin{array}{c}1.252 \\
(0.525)\end{array}$ & $\begin{array}{c}0.284 \\
(0.035)\end{array}$ & $\begin{array}{c}0.268 \\
(0.063)\end{array}$ & $\begin{array}{c}0.939 \\
(0.014)\end{array}$ & $\begin{array}{c}0.949 \\
(0.019)\end{array}$ & $\begin{array}{c}-0.009 \\
(0.456)\end{array}$ & $\begin{array}{c}-0.244 \\
(0.440)\end{array}$ \\
\hline Treasury debt & $\begin{array}{c}0.269 \\
(0.131)\end{array}$ & $\begin{array}{c}0.090 \\
(0.021)\end{array}$ & $\begin{array}{c}0.031 \\
(0.038)\end{array}$ & $\begin{array}{c}0.316 \\
(0.065)\end{array}$ & $\begin{array}{c}0.327 \\
(0.061)\end{array}$ & $\begin{array}{c}0.913 \\
(0.029)\end{array}$ & $\begin{array}{c}0.943 \\
(0.015)\end{array}$ & $\begin{array}{c}0.111 \\
(0.061)\end{array}$ & $\begin{array}{c}0.090 \\
(0.060)\end{array}$ \\
\hline Agency debt & $\begin{array}{c}0.146 \\
(0.094)\end{array}$ & $\begin{array}{c}0.025 \\
(0.021)\end{array}$ & $\begin{array}{c}0.091 \\
(0.051)\end{array}$ & $\begin{array}{c}0.271 \\
(0.066)\end{array}$ & $\begin{array}{c}0.342 \\
(0.069)\end{array}$ & $\begin{array}{c}0.941 \\
(0.019)\end{array}$ & $\begin{array}{c}0.911 \\
(0.030)\end{array}$ & $\begin{array}{c}0.162 \\
(0.066)\end{array}$ & $\begin{array}{c}0.122 \\
(0.066)\end{array}$ \\
\hline Municipal debt & $\begin{array}{c}0.152 \\
(0.152)\end{array}$ & $\begin{array}{c}0.080 \\
(0.044)\end{array}$ & $\begin{array}{c}0.247 \\
(0.130)\end{array}$ & $\begin{array}{c}0.424 \\
(0.141)\end{array}$ & $\begin{array}{c}0.238 \\
(0.078)\end{array}$ & $\begin{array}{c}0.889 \\
(0.077)\end{array}$ & $\begin{array}{c}0.914 \\
(0.025)\end{array}$ & $\begin{array}{c}0.183 \\
(0.095)\end{array}$ & $\begin{array}{c}0.166 \\
(0.096)\end{array}$ \\
\hline Corp. debt & $\begin{array}{c}0.201 \\
(0.163)\end{array}$ & $\begin{array}{c}0.033 \\
(0.087)\end{array}$ & $\begin{array}{c}0.073 \\
(0.482)\end{array}$ & $\begin{array}{c}0.245 \\
(0.138)\end{array}$ & $\begin{array}{c}0.373 \\
(0.336)\end{array}$ & $\begin{array}{c}0.942 \\
(0.053)\end{array}$ & $\begin{array}{c}0.928 \\
(0.177)\end{array}$ & $\begin{array}{c}0.085 \\
(0.101)\end{array}$ & $\begin{array}{c}0.058 \\
(0.096)\end{array}$ \\
\hline DB pensions & $\begin{array}{c}0.210 \\
(0.126)\end{array}$ & $\begin{array}{c}0.000 \\
(0.000)\end{array}$ & $\begin{array}{c}0.002 \\
(0.001)\end{array}$ & $\begin{array}{c}0.218 \\
(0.065)\end{array}$ & $\begin{array}{c}0.431 \\
(0.102)\end{array}$ & $\begin{array}{c}0.947 \\
(0.028)\end{array}$ & $\begin{array}{c}0.902 \\
(0.047)\end{array}$ & $\begin{array}{c}0.160 \\
(0.060)\end{array}$ & $\begin{array}{c}0.134 \\
(0.060)\end{array}$ \\
\hline Real estate & $\begin{array}{c}0.256 \\
(0.125)\end{array}$ & $\begin{array}{c}0.014 \\
(0.017)\end{array}$ & $\begin{array}{c}0.024 \\
(0.028)\end{array}$ & $\begin{array}{c}0.304 \\
(0.065)\end{array}$ & $\begin{array}{c}0.321 \\
(0.065)\end{array}$ & $\begin{array}{c}0.918 \\
(0.028)\end{array}$ & $\begin{array}{c}0.947 \\
(0.017)\end{array}$ & $\begin{array}{c}-0.093 \\
(0.034)\end{array}$ & $\begin{array}{c}-0.072 \\
(0.032)\end{array}$ \\
\hline Agg. wealth & & & & & & & & $\begin{array}{c}0.013 \\
(0.150)\end{array}$ & $\begin{array}{c}-0.049 \\
(0.146)\end{array}$ \\
\hline \multicolumn{10}{|c|}{ Panel B: Additional details for second-stage return regressions } \\
\hline & \multicolumn{3}{|c|}{$\begin{array}{c}\text { Joint test of intercepts } \\
\text { equal to zero }\end{array}$} & \multicolumn{2}{|c|}{$\begin{array}{l}\text { Risk-aversion } \\
\text { coefficient }\end{array}$} & \multicolumn{2}{|c|}{$\begin{array}{l}\text { Control for } \\
\text { lagged returns }\end{array}$} & \multicolumn{2}{|c|}{ Model fit } \\
\hline Case & \multicolumn{3}{|c|}{$p\left(\mu_{1}=\cdots=\mu_{9}=0\right)$} & \multicolumn{2}{|c|}{$\gamma$} & \multicolumn{2}{|c|}{ Include $R_{j, t-1} ?$} & \multicolumn{2}{|c|}{$R^{2}(\%)$} \\
\hline (1) & \multicolumn{3}{|c|}{0.044} & \multicolumn{2}{|c|}{$\begin{array}{c}7.316 \\
(4.071) \\
{[0.040]}\end{array}$} & \multicolumn{2}{|c|}{ No } & \multicolumn{2}{|c|}{1.09} \\
\hline$(2)$ & \multicolumn{3}{|c|}{0.238} & $\begin{array}{l}7.5 \\
(3.9 \\
{[0.0}\end{array}$ & $\begin{array}{l}34 \\
46) \\
29]\end{array}$ & \multicolumn{2}{|c|}{ Yes } & \multicolumn{2}{|c|}{4.86} \\
\hline
\end{tabular}




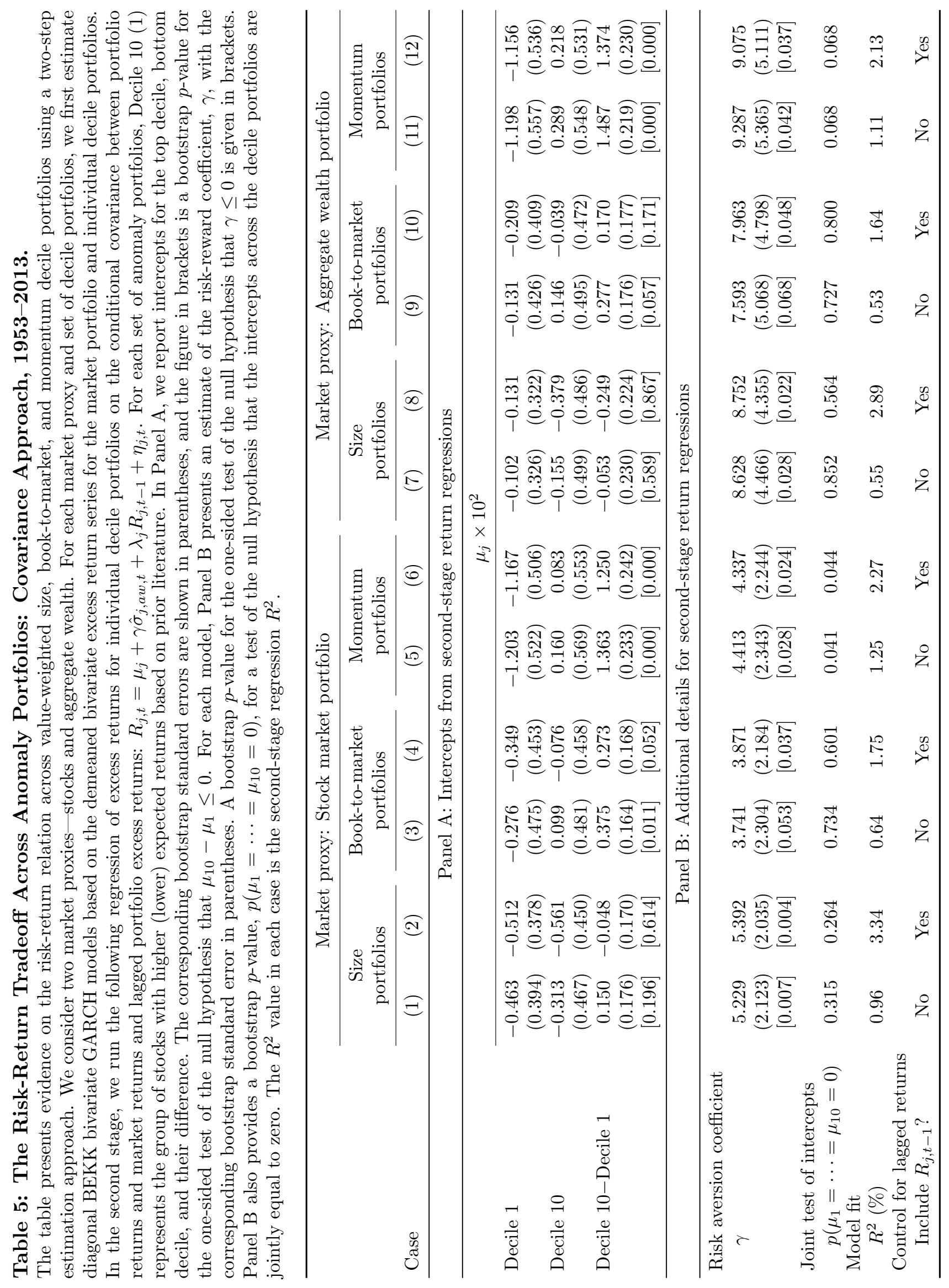



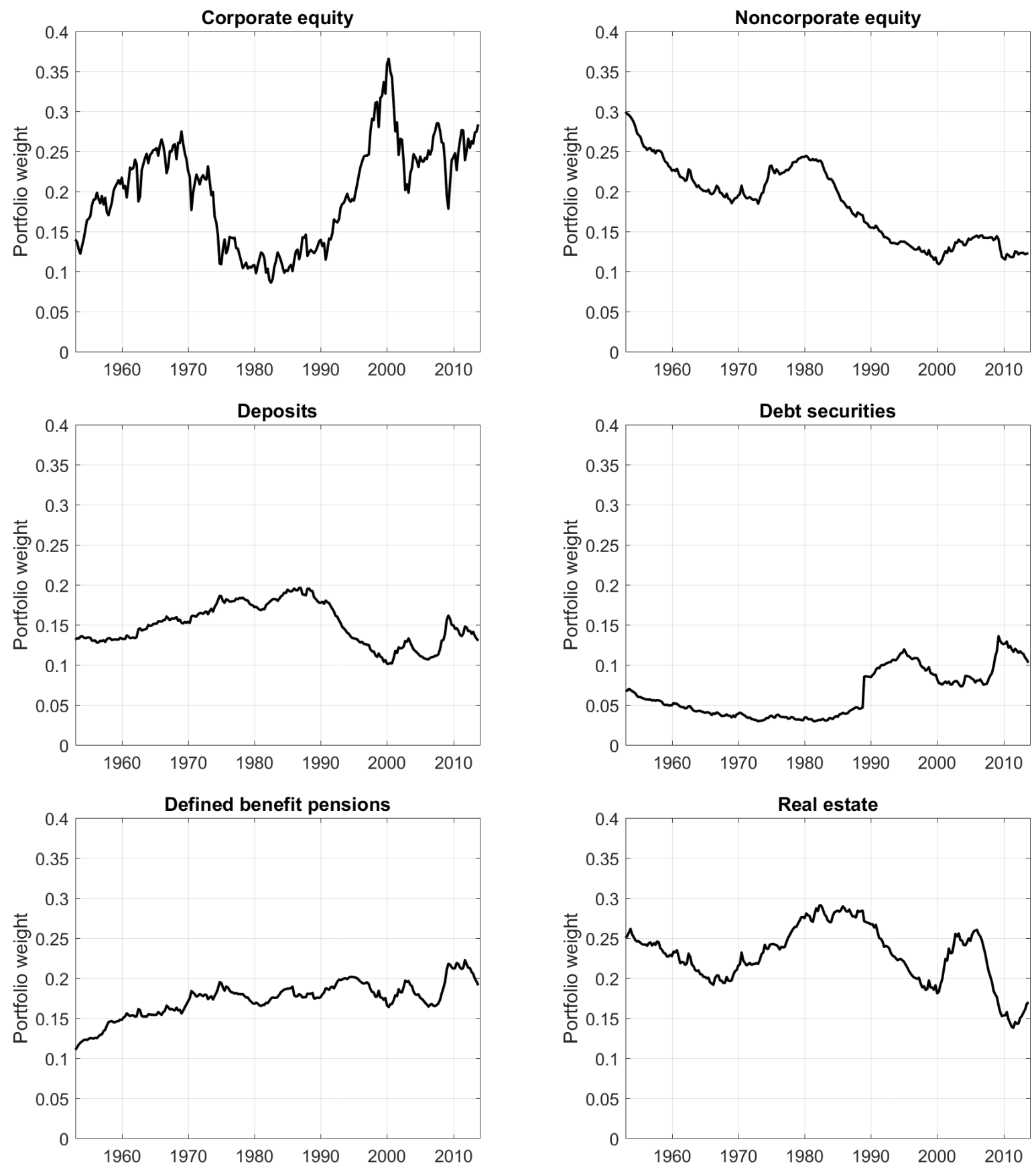

Figure 1: Time Series of Aggregate Wealth Portfolio Weights, 1953-2013.

The figure shows the time series of portfolio weights for assets included in the aggregate wealth portfolio. The "debt securities" category includes Treasury debt, agency debt, municipal debt, and corporate debt. The primary data source for estimating the portfolio weight for each asset class is the Federal Reserve Flow of Funds Table B.100 (Balance Sheet of Households and Nonprofit Organizations), which reports holdings of each asset class on a quarterly basis. In determining the aggregate values for the individual asset classes, we also make use of Flow of Funds Tables B.100.e, L.116, L.117.c, and L.121 as described in the Internet Appendix. 


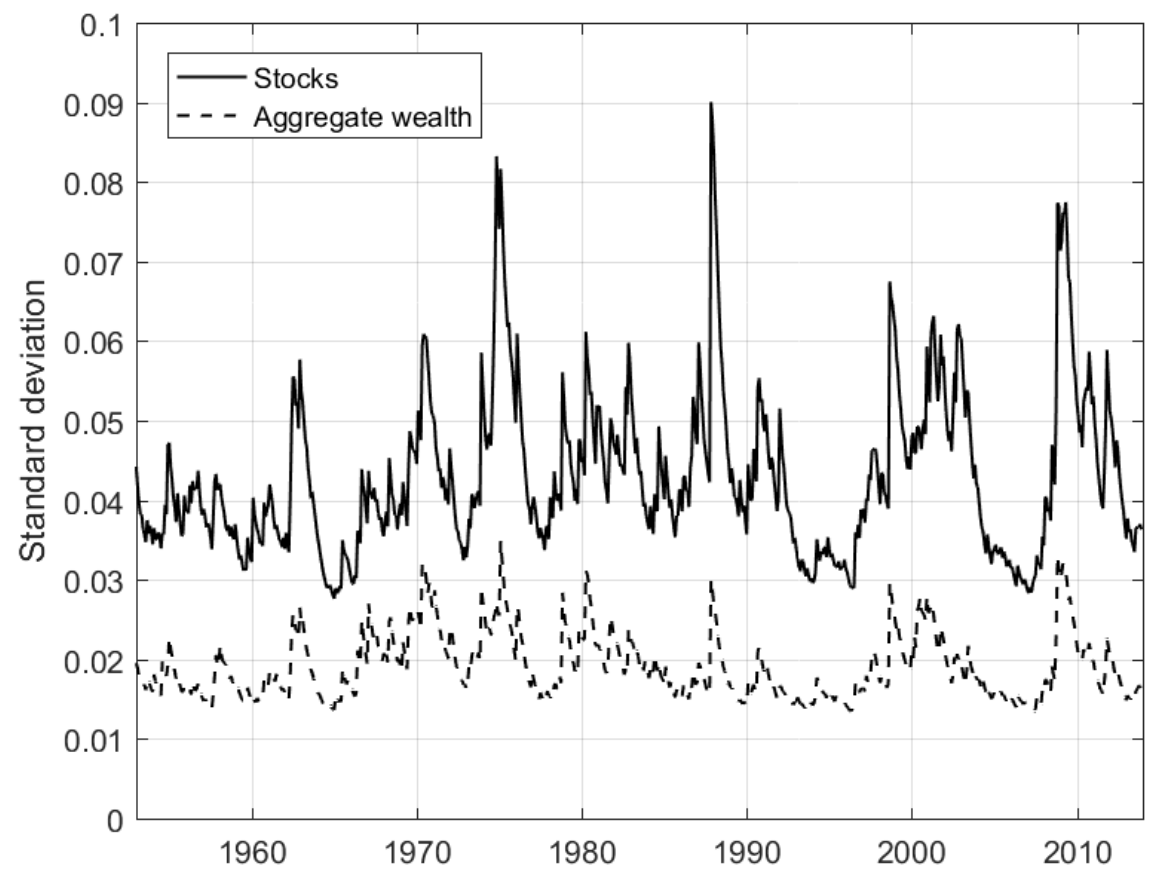

Figure 2: Comparison of Volatility Estimates, 1953-2013.

The figure shows GARCH estimates of conditional volatility for the stock market portfolio (solid line) and aggregate wealth portfolio (dashed line). We assume that the demeaned excess return in month $t$ for a given market portfolio $i$ (i.e., the stock market or aggregate wealth), $R_{i, t}-\bar{R}_{i}$, is normally distributed with mean zero and variance $\sigma_{i, t}^{2}$. The conditional variance evolves according to a $\operatorname{GARCH}(1,1)$ process: $\sigma_{i, t}^{2}=\omega+\alpha \varepsilon_{i, t-1}^{2}+\delta \sigma_{i, t-1}^{2}$. The plot shows the conditional standard deviations. We estimate GARCH parameters using maximum likelihood estimation (MLE), and the corresponding parameter estimates for the stock market portfolio and aggregate wealth portfolio are provided in Table 2 , 